\title{
Phenomenal evidence and factive evidence
}

\author{
Susanna Schellenberg ${ }^{1}$
}

Published online: 28 August 2015

(C) Springer Science+Business Media Dordrecht 2015

\begin{abstract}
Perceptions guide our actions and provide us with evidence of the world around us. Illusions and hallucinations can mislead us: they may prompt as to act in ways that do not mesh with the world around us and they may lead us to form false beliefs about that world. The capacity view provides an account of evidence that does justice to these two facts. It shows in virtue of what illusions and hallucinations mislead us and prompt us to act. Moreover, it shows in virtue of what we are in a better epistemic position when we perceive than when we hallucination. In this paper, I develop the capacity view, that is, the view that perceptual experience has epistemic force in virtue of the epistemic and metaphysical primacy of the perceptual capacities employed in perception. By grounding the epistemic force of experience in facts about the metaphysical structure of experience, the capacity view is not only an externalist view, but moreover a naturalistic view of the epistemology of perceptual experience. So it is an externalist and naturalistic alternative to reliabilism. I discuss the repercussions of this view for the justification of beliefs and the epistemic transparency of mental states, as well as, familiar problem cases.
\end{abstract}

Keywords Phenomenal evidence - Factive evidence - Perception - Capacities · Justification $\cdot$ Epistemic transparency $\cdot$ Speckled hen $\cdot$ Evil demon

\section{Introduction}

What is evidence? According to the capacity view, evidence and allied notions such as justification and knowledge are to be understood in terms of the mental capacities employed. The notion of a capacity is understood to be explanatorily basic. It is

Susanna Schellenberg

susanna.schellenberg@rutgers.edu

1 Rutgers, New Brunswick, NJ, USA 
because a given subject is employing a mental capacity with a certain nature that her mental states have epistemic force. Among capacity views there is a distinction to be drawn between normative capacity views, on which mental capacities are understood as virtues or in other normative ways (Sosa 1991, 2006, 2007; Greco 2001, 2010; Bergmann 2006), and capacity views that forego normative terms (Burge 2003; Graham 2011; Schellenberg 2013a, 2014a).

The capacity view can be contrasted with a number of alternative recent epistemological approaches. Dogmatism and evidential internalism treat conscious mental states as explanatorily basic and posit a particular rule for justification, namely, that if it perceptually seems that $p$, then one has prima facie justification for $p$ (Pollock 1974; Feldman and Conee 1985; Pryor 2000; Huemer 2007, among others). ${ }^{1}$ The knowledge-first view treats knowledge as explanatorily basic and analyzes justification in terms of a deficiency of knowledge (McDowell 1982; Williamson 2000; Millar 2008; Nagel 2013; Byrne 2014 among others). Reliabilism treats the reliability of the perceptual or cognitive system as explanatorily basic and analyzes evidence and justification as a product of this reliable system-be it in virtue of a reliable indicator or a reliable process (Goldman 1979, 1986; Lyons 2009 among others). By contrast, capacity views treat capacities as explanatorily basic and analyze evidence, justification, and knowledge as a product of the capacities employed. So on the first cluster of views, conscious mental states are explanatorily basic, on the second cluster knowledge, on the third reliability, and on the fourth capacities. $^{2}$ These options are neither exclusive nor exhaustive. One might think that more than one of these four elements are explanatorily basic, or one might think that what is explanatorily basic is something else entirely. Nevertheless, these four approaches are the main current options.

When I say that conscious mental states, reliability, knowledge, or capacities are explanatorily basic, I do not mean that the relevant views are committed to holding that one cannot give an analysis of these concepts. ${ }^{3}$ I mean rather that they are the fundamental elements in terms of which an epistemological account is developed. Most views appeal to conscious mental states and reliability; many appeal to some form of mental capacity. The key question is what the basic elements are in terms of which an epistemological account is developed. On Williamson's view, for example, this basic element is knowledge, rather than conscious mental states, reliability, or methods-even if his view appeals to all three concepts along the way. ${ }^{4}$

\footnotetext{
${ }^{1}$ Naturally, there are big differences between these different views but what they all have in common is that they treat conscious mental states as explanatory basic.

${ }^{2}$ One could make the case that insofar as on some of the views categorized as capacity views it is essential that the capacities in play are reliable, those views should better be classified as reliabilist views.

${ }^{3}$ Williamson (2000) famously holds that knowledge cannot be analyzed. But one can accept the insights of his account of justification as derivative from knowledge while rejecting his view that knowledge cannot be analyzed.

${ }^{4}$ Williamson's notion of method can be understood as a kind of capacity.
} 
I have recently developed a particular version of the capacity view, one that is distinctly non-normative and non-reliabilist. ${ }^{5}$ In this paper, I will briefly state the basic commitments of that view and will then discuss its repercussions for the justification of beliefs and the epistemic transparency of mental states. In light of these discussions, I will explore the implications of the view for familiar problem cases. With "the capacity view", I henceforth mean the particular non-normative and non-reliabilist capacity view that I have developed and will now present.

\section{The capacity view}

The basic idea underlying the capacity view is that perceptual states are systematically linked to what they are of in the good case, that is, the case of a successful perception, and thereby provide evidence for what they are of in the good case. Consider a perceiver who sees a white cup. Let's call him Percy. Percy is in the good case. His perceptual state is systematically linked to the white cup he is seeing in that he is perceptually related to that very cup. His perceptual state is of the white cup and it provides him evidence that the white cup present. In more detail the idea is that perceptual experience is a matter of employing perceptual capacities that allow us, in the good case, to discriminate and single out particulars in our environment. Sensory states are understood as ensuing from employing such capacities in a sensory mode, that is, modes such as seeing, hearing, touching, smelling, or tasting. If the same perceptual capacities are employed in the same sensory mode, the same sensory state is constituted. So the employment of these perceptual capacities in a given sensory mode grounds the sensory state.

As I will explain shortly, employing perceptual capacities constitutes the content of experience. This entails that the capacity view is a weak version of representationalism, that is, a version of representationalism on which the sensory character of experience is grounded in the content of experience. Any representationalist view needs to explain the notion of representation in play. On the capacity view, representations are understood as yielded by employing perceptual capacities. The capacities in play are individuated by the mind-independent particulars they single out in the good case. Perceptual states can thereby be seen as providing evidence for what they are of in the good case, since, by their nature, they function to single out what they in fact single out in the good case.

When we hallucinate, we employ these very perceptual capacities-albeit failing to single out the relevant particulars. The perceptual capacities are, even when employed in the bad case, systematically linked to what they are of in the good case. After all, they function to do what they do in the good case, namely discriminate and single out particulars in the environment. Even if one happens to be in the bad case, the capacities employed do not cease to have this function. Since perceptual capacities function to single out particulars, employing them is the basis for the intentional directedness to particulars in perception. Thus employing perceptual

\footnotetext{
5 See my (2013a). For critical discussion, see (Byrne 2014).
} 
capacities accounts for the intentional directedness to a seeming particular object and so accounts for the fact that when we suffer a non-veridical hallucination as of an object, it seems to us as if a particular object is present (even though no such object is present). When we hallucinate, we have some evidence for believing that things are how they seem to us, since perceptual capacities are employed. We have this evidence, even though things are in fact not how they seem to us.

The perceptual capacities can be understood as discriminatory, selective capacities. For the purposes of this paper we can remain neutral on whether they are low-level capacities or more high-level concepts. That said, in so far as perception is a low-level ability that beings have which are significantly less cognitively sophisticated than we are, there are reasons to think that the perceptual capacities that constitute perceptual states are low-level discriminatory capacities rather than more high-level concepts. However, nothing in this paper hinges on this issue.

It is worth highlighting that I am not arguing that all capacities employed in perception have repercussions for our sensory states and the epistemic force of experience. The idea is not that whenever we use, say, a discriminatory, selective capacity, we are in a sensory state. The visual system makes use of many capacities on a subpersonal level. The thesis in play is rather that the nature of sensory states is best understood in terms of employing perceptual capacities, rather than in terms of awareness relations to strange particulars, such as sense data or qualia, or abstract entities, such as properties or propositions. ${ }^{6}$ We can accept this thesis while acknowledging that there are many capacities the employment of which have no repercussions for our phenomenal lives. The perceptual capacities of concern here are individuated by the types of particulars they function to single out. For the purposes of this paper, we can understand types of particulars as natural kinds in the environment. Such natural kinds include shapes and more controversially colors, as well as kinds of objects and events. ${ }^{7}$ So while perceptual capacities are individuated by types of mind-independent particulars, sensory states are individuated by the perceptual capacities employed. In this sense, the account provided is an externalist account of sensory states. It is modestly externalist insofar as the perceptual capacities can be employed while failing to single out any particular of the type they function to single out.

To illustrate this, compare Percy, who perceives a white cup, with Hallie, who hallucinates a white cup. While perceiving Percy is perceptually related to a white cup, hallucinating Hallie is not. It seems to Hallie that she is perceiving a white cup, but of course she is not. We can analyze the perceptual capacities Hallie employs with respect to the conditions for which they function (good cases), despite the fact that Hallie is not currently in such a condition. There is nothing wrong with Hallie's perceptual system. The problem is that her environment is not playing along. Since her perceptual capacities are working well with respect to the conditions for which

\footnotetext{
${ }^{6}$ For the contrast between analyzing sensory character in terms of awareness relations to peculiar entities, such as strange particulars or abstract entities, on the one hand, and understanding sensory character in terms of a mental activity, such as employing perceptual capacities, see my (2011a).

7 For a detailed development of such a color realist view, see Byrne and Hilbert (2003).
} 
they function, Hallie's perceptual state has at least some merit: it is a product of employing her perceptual capacities. The way in which Hallie is failing is simply that she is not singling out relevant particulars.

So both Percy and Hallie employ perceptual capacities, and both of their perceptual capacities are systematically linked to what they are of in the good case in that they function to single out particulars. For this reason both Percy and Hallie's perceptual states have some evidential merit. But only Percy is actually singling out relevant particulars. By singling out the relevant particulars, Percy has additional evidence.

The distinction between the capacities employed and what, if anything, they single out brings into focus two ways to individuate perceptual states. On one way, the relevant features that characterize the state are the same: the same perceptual capacities are employed. On the other way, the relevant features that characterize the state are different: when we perceive, we successfully single out environmental particulars; when we hallucinate, we fail to do so. The capacity view unifies these two ways of individuating perceptual states. What Percy and Hallie's perceptual states have in common is a content type. The content type is constituted by the perceptual capacities employed and covaries one-to-one with the sensory state. Where their mental states differ is in the token content. The token content of perception is a singular content that is constituted by successfully employing these capacities in an environment, thereby singling out particulars in said environment. The token content of hallucination is defective insofar as the capacities are employed baselessly: Hallie fails to single out what she purports to single out. One way to analyze what it means for the content to be defective is to say that it is gappy. While the token singular content covaries with the environment in which the relevant capacities are employed, the content type does not covary with the environment in which they are employed.

It is important to note that the content type is not a general content, but rather a potentially particularized content. It is a kind of content schema. An analogy will help motivate this way of understanding content types. If I have a thought as of a white cup, but there is no white cup present, I fail to refer. In such a case, the content of my thought is not singular. After all, I failed to refer. But it is not a general content either. After all, I purport to refer to a particular object. So the content has the form of a singular content, while failing to be a token singular content. Similarly, in the case of perceptual experience, the content type is neither a complete general proposition, nor a gappy token content. There are more options than these two, namely, a potentially particularized content. The content of a perceptual experience is structured by two levels: a potentially particularized content type and a token content. The content of a hallucination is likewise structured by two levels: a potentially particularized content type (which it might share in common with a perceptual experience) and a token content, which (given that there is no relevant particular being perceived) I take to be a gappy token content. Neither the gappy token content nor the potentially particularized content type is a singular content, and neither is a general content.

By unifying the two ways of individuating perceptual states via the perceptual capacities employed, externalist and internalist intuitions about perceptual 
experience can be accounted for. The capacity view allows us to say that there is a metaphysically substantial common element between the good and the bad case, thus allowing us to avoid any disjunctivist implications, while acknowledging that the content of perception is singular.

The distinction between two levels of perceptual content gives rise to two levels of perceptual evidence: phenomenal evidence and factive evidence. Phenomenal evidence is individuated by the content type that is in turn individuated by the perceptual capacities employed. Factive evidence is individuated by the token content that ensues from employing these capacities successfully in a particular environment. In the good case, perceptual experience provides us with both phenomenal and factive evidence. In the bad case, perceptual experience provides us only with phenomenal evidence. There is no factive evidence in the bad case because the capacities were not employed successfully and the ensuing token content is defective.

By introducing the notion of phenomenal evidence, we can explain what evidence Percy and Hallie have in common. Moreover, we can explain in virtue of what hallucinating Hallie is not simply blameworthy for her belief. She has reason for believing that there is a white cup on her desk. After all, for all she can tell, there is a white cup on her desk. She has phenomenal evidence that supports her belief.

By introducing the notion of factive evidence, we can explain in virtue of what Percy is in a better evidential position than Hallie. While his evidential position may seem to him to be indistinguishable from that of Hallie's, Percy has, unbeknownst to him, additional factive evidence and thus evidence that the particular white cup to which he is perceptually related is in fact before him. Thus, Percy has evidence that supports a singular thought about his environment.

The rational source of both kinds of evidence lies in employing perceptual capacities that we have in virtue of being perceivers. Sensory states provide phenomenal evidence since the perceptual capacities employed in the bad case are systematically linked to their employment in the good case in the sense that the perceptual capacities employed in the bad case are explanatorily and metaphysically parasitic on their employment in the good case. There is an explanatory primacy of the good over the bad case, since giving an analysis of the perceptual capacities employed in the bad case requires appealing to their role in the good case. There is a metaphysical primacy of the good over the bad case insofar as perceptual capacities are determined by relations between perceivers and their environment insofar as the function of the capacity is to differentiate and single out, say, instances of red in perception.

Why should we accept these twin primacy claims? The function of perceptual capacities is to differentiate and single out a kind of particular, say, instances of red. It is unclear what it would mean to possess a perceptual capacity, the very function of which is to single out a kind of particular, without being in a position to single out such a particular when perceptually related to one, and nothing else is amiss. Say we possess the capacity to discriminate and single out red from other colors. Were we not in a position to use our capacity to single out red in our environment, when perceptually related to an instance of red and with nothing else amiss, we would not count as possessing the capacity. This is a minimal condition for possessing a 
perceptual capacity. Now it might be that we are always unlucky and are never perceptually related to red things and so never in a position to single out anything red in our environment. The minimal condition, however, still holds. While perceptual capacities can be employed in hallucination, they are determined by relations between perceivers and their environment in so far as the function of the capacity is to differentiate and single out, say, instances of red in perception. In this sense, sensory states are systematically linked to what they single out in the good case. As a consequence, there is a metaphysical priority of the good over the bad case. Sensory states are rational to heed in virtue of being systematically linked to what they single out in the good case. In virtue of this metaphysical primacy of the good over the bad case, there is an explanatory primacy of the good over the bad case.

The analysis of the epistemic role of phenomenal evidence in virtue of a notion of systematic linkage carries over to an analysis of the epistemic role of factive evidence. After all, in the case of a perception, there is an ideal link between one's perceptual state and the environment: one is perceptually related to one's environment. So on the proposed view, the epistemic power of perceptual experience is explained in terms of metaphysical facts about perceptual experience. Thus, the epistemic force of experience is grounded in facts about the physical world.

Phenomenal evidence and factive evidence are epistemically united in so far as both are provided by mental states that are constituted by employing perceptual capacities. In showing that both kinds of evidence have their rational source in employing perceptual capacities, the suggested view provides a unified account of perceptual evidence-one which is distinctively capacity-based, non-normative, and non-reliabilist.

Factive evidence provides additional evidence that is different from phenomenal evidence. It is evidence of a different kind insofar as the systematic linkage to the environment is stronger than the one governing phenomenal evidence. More specifically, it is evidence of a different kind because it is provided by successfully employing perceptual capacities in a particular environment. So factive evidence provides a rationality boost beyond the one that a perceiver already has from phenomenal evidence. This explains why Percy is in a better evidential position than Hallie. Now from the first-person perspective, one may not be able to tell the difference between a hallucination in which one has only phenomenal evidence, and a perception in which one has both phenomenal and factive evidence. But we need not think that what is accessible from the first-person perspective dictates what is rational to heed.

While this view of perceptual evidence is externalist, it makes room for a phenomenal conception of evidence. So, in contrast to externalist views such as Williamson's, the capacity view shows that we have at least some evidence provided directly through experience in the bad case: we have phenomenal evidence. ${ }^{8}$ In contrast to evidential internalist views (cf. Pollock 1974; Feldman and

\footnotetext{
8 According to Williamson, we have only evidence provided by an appearance proposition in the bad case. For discussion of the problems with this, see my (2013a).
} 
Conee 1985; Pryor 2000), the capacity view shows that we have more evidence in the good than the bad case: we have additional factive evidence. So the defended view provides us with something that neither factive evidentialists nor evidential internalists can supply.

\section{Evidence and justification}

While the capacity view has some consequences for the justificatory power of perceptual experience, it does not dictate a particular view about justification. It is compatible with a range of views about the relationship between the evidence that experience provides and any beliefs formed on the basis of that evidence. ${ }^{9}$ Moreover, it is compatible with a range of views about how and why the evidence provided by perceptual experiences supports beliefs. My focus is on what it is about experience that makes it something that provides us with evidence, not what the relationship is between this evidence and the rational role of beliefs formed on the basis of the experience.

For the sake of simplicity and definiteness, I will work with the assumption that having more evidence for a proposition $p$ means that $p$ is better justified. Moreover, for the purposes of this paper, I will treat the notion of being in a better epistemic position in terms of being better justified, since this is the most straightforward way to think about the quality of an epistemic position. ${ }^{10}$ While the capacity view is compatible with a range of views about the relationship between the evidence that experience provides and any beliefs formed on the basis of that evidence, it explains in virtue of what one is in a better epistemic position when one perceives than when one hallucinates. Let's assume Percy and Hallie both form a belief that they express with "that cup is white". We can leave open for now whether Percy's belief has the same content as Hallie's belief. The important point for present purposes is that Percy and Hallie would express their beliefs in the same way. After all, their environment seems the same way to them. Insofar as Percy's belief is supported by more and better evidence than Hallie's, Percy's belief is better justified than Hallie's. More generally, when one forms a belief on the basis of perceiving a white cup, one's belief is better justified than when one forms a belief on the basis of hallucinating a white cup. One's evidence in the good case justifies any supported belief to a higher degree than does one's evidence in the bad case. ${ }^{11}$

\footnotetext{
${ }^{9}$ For a discussion of the relationship between evidence and justification, see McGrath and Fantl (2002, 2009).

${ }^{10}$ An alternative would be to think of the quality of the epistemic position as an aspect of knowledge distinct from justification. On this way of thinking, one would say that the perceiver and the hallucinator are equally justified, but the perceiver is still in a better epistemic position in virtue of having knowledge, where this difference in epistemic position makes the difference between knowledge and ignorance.

11 An interesting question is what the connection is between the strength of the evidence we have for a proposition and our confidence in that proposition. For a discussion of the relationship between having evidence for $p$ and having confidence in $p$, see Neta $(2003,2008)$ and Silins (2005).
} 
Now if one cannot tell that there is a difference in evidence, let alone what the difference is, what effect will the difference in evidence have for one's cognitive life? In response, we can say that the difference in evidence will have repercussions for what one is justified in believing. Factive perceptual evidence is evidence of particulars in a perceiver's environment and so justifies singular thoughts about her environment. Phenomenal evidence is not evidence of particulars in a perceiver's environment. More generally, we can say that any perception can give rise to a number of different beliefs, including singular beliefs and general beliefs. The factive evidence provided by my perception will give support to both singular beliefs and general beliefs. Phenomenal evidence, by contrast, supports only general beliefs. The point generalizes beyond experience: if you have propositional justification for the singular belief, "that cup is white", you will also have propositional justification for the general belief it entails: "There is a white cup". That follows from a relatively simple schema for deductive closure.

In short, while factive evidence supports singular beliefs as well as general beliefs, phenomenal evidence supports only general beliefs. So while one cannot tell whether one is in the good case or the bad case and so cannot tell whether one has factive evidence in addition to phenomenal evidence, it makes an epistemic difference to have factive evidence in addition to phenomenal evidence, in that more of one's beliefs will be justified.

Another way of expressing the same idea is with regard to the logical role of demonstratives and how we articulate the content of experience. The content type and token content of any subjectively indistinguishable perceptual experiences can be articulated in the very same way in natural language. They better be. After all, a perception and a hallucination can be subjectively indistinguishable and one should be able to articulate subjectively indistinguishable experiences in the same way. Consider again a perceptual experience of a white cup. The content type and the singular token content can both be articulated with "that cup is white". The demonstrative "that", however, will play a different logical role in the two cases. In the content type, the demonstrative plays a character role-to use Kaplan's terminology (cf. Kaplan 1989). It purports to refer to whatever particular, if any, there might be, without saying which it happens to be on a given occasion. By contrast, in the singular token content, the demonstrative plays a content role-in Kaplan's sense of "content". It refers to a specific particular singled out on a given occasion-in the case of a perception, the very thing to which the perceiver is perceptually related. So, unbeknownst to the experiencing subject, the two contents will play different roles in inferences and so have different evidential force. In the next section, I will discuss this set of issues in more detail.

\section{Epistemic transparency}

The capacity view entails that one is not always in a position to know what evidence one has. So the capacity view entails that the following principle is false. 
Evidential Transparency: For any evidence $E$, whenever one is suitably alert and conceptually sophisticated, one is in a position to know whether one has $E$.

The evidential transparency principle is a particular version of the more general principle that mental states are epistemically transparent-assuming that the evidence one has is constituted by the mental state one is in. ${ }^{12}$ The idea that evidence is a matter of what mental state one is in does not imply an internalist view of evidence. After all, mental states can be externally individuated. Indeed, the capacity view posits that mental states are at least in part externally individuated. Following Williamson, we can specify the principle that mental states are epistemically transparent in the following way:

Epistemic Transparency: For every mental state $M$, whenever one is suitably alert and conceptually sophisticated, one is in a position to know whether one is in $M .^{13}$

Evidential Transparency is a particular version of Epistemic Transparency insofar as it posits that subject $S$ has evidence $E$ because she is in a certain mental state $M$ that provides $E$. The capacity view entails that Epistemic Transparency is false and so entails that evidence is not epistemically transparent. Now it would put the cart before the horse to reject the epistemic transparency principle so as to uphold the capacity view. But as I will show, there are independent reasons to reject the principle.

First, let's get clearer about why the capacity view entails that one is not always in a position to know what evidence one has. Consider the case in which one has evidence $E$. If evidence is externally individuated, then one will not always be in a position to know that one has evidence $E$. Similarly, if one does not have evidence $E$ and evidence is externally individuated, one will not always be in a position to know that one does not have evidence $E$. To show this, we can formulate the following argument:

\section{Argument from the evidence we have in perception and hallucination:}

1. If one perceives a white cup, then one has factive evidence of that white cup.

2. If one suffers a hallucination as of a white cup, then one does not have factive evidence of a white cup.

3. It is not transparent whether one perceives a white cup or suffers a hallucination as of white cup.

4. It is not transparent whether or not one has factive evidence of a white cup.

5. If it is not transparent whether or not one has factive evidence of a white cup, then mental states are not epistemically transparent.

6. Therefore, mental states are not epistemically transparent.

\footnotetext{
${ }^{12}$ I am taking for granted here that being in a mental state is closed under constitution: what is constituted by the mental is itself mental. For an argument for the thesis that the evidence one has is a matter of what mental state one is in, see Williamson (2000).

${ }^{13}$ See Williamson (2000: 11) for both principles. For a critical discussion of both principles, see Smithies (2012).
} 
Premise 1 and Premise 2 are just consequences of the capacity view. Premise 3 follows from the generally accepted thesis that a perception and hallucination could be subjectively indistinguishable. If Premises 1-3 hold, then-given the capacity view-one is not always in a position to know what evidence one has.

Now what independent reasons do we have for rejecting Evidential Transparency or more generally Epistemic Transparency? One such reason is given by the argument from the subjective indistinguishability of perception and hallucination:

Argument from the subjective indistinguishability of perception and hallucination:

1. If mental states were epistemically transparent, it would be epistemically transparent to a subject $S$ whether she is perceiving or hallucinating.

2. It is not epistemically transparent to $S$ whether she is perceiving or hallucinating.

3. Therefore, mental states are not epistemically transparent.

Consider the case in which Hallie is hallucinating that there is a white cup on the table. It seems to her as if a particular white cup is in front of her-that is, it seems to her as if she is in the good case. That is just what it means for a hallucination to be subjectively indistinguishable from a perception. However, it only seems to her that a particular cup is present. So she does not have factive evidence of the presence of a particular cup. She has mere phenomenal evidence. She does not, however, know that she has only phenomenal evidence. She does not know that she does not have factive evidence. After all, if it were accessible to her whether she has factive evidence or only phenomenal evidence, a perception and a hallucination could never be subjectively indistinguishable. So it is not transparent to Hallie that she is hallucinating.

An argument analogous to the argument from the subjective indistinguishability of perception and hallucination can be made regarding the perception of qualitatively identical, yet numerically distinct particulars:

Argument from perceiving numerically distinct but qualitatively indistinguishable objects:

1. If mental states were epistemically transparent, it would be epistemically transparent to a given subject $S$ whether she is perceiving $\alpha$ or $\beta$, where $\alpha$ and $\beta$ are numerically distinct yet qualitatively identical particulars.

2. It is not epistemically transparent to $S$ whether she is perceiving $\alpha$ or $\beta$.

3. Therefore, mental states are not epistemically transparent.

Both arguments show that factive mental states are not epistemically transparent. If they were, one would always know whether one is perceiving or hallucinating. Moreover, one would know whether one is perceiving $\alpha$ or $\beta$, even if $\alpha$ and $\beta$ are qualitatively identical and all else is equal. Both are counterintuitive. So there are independent reasons to reject that mental states are epistemically transparent.

To be clear, the capacity view does not presuppose that one could never have full access to one's evidence, but only that one is never in a position to know everything about the specific mental state one is in. A different way of articulating the same 
point is with regard to the $\mathrm{KK}$ principle. While perception yields perceptual knowledge, we do not know when an experience yields knowledge. The epistemic transparency principle has it that we know what mental state we are in if we are suitably alert and conceptually sophisticated. So epistemic transparency would then entail that, so long as we are suitably alert and conceptually sophisticated, in perception we not only attain the mental state of knowledge but also know that we obtain the mental state of knowledge (since our being in the mental state of knowledge is transparent to us). But this cannot be right. In perception we have mental state $M$, but we lack knowledge that we have mental state $M$ since we do not know whether we are perceiving or hallucinating. Hence we have a mental state $M$ that is non-transparent. Indeed, we do not know whether we are perceiving or hallucinating, and so when we are perceiving, we do not know that we know. So the KK principle is false.

The more general lesson to be learned from this argument is that one may know things without knowing that one knows them. But even if one does not know what epistemic position one is in, one may nonetheless exploit that epistemic position. ${ }^{14}$ After all, one has evidence $E$, and having that evidence will have repercussions for one's cognitive and epistemic life. The evidence will justify beliefs that would not be justified if one did not have that evidence.

A second independent rationale in support of the thesis that mental states are not epistemically transparent is motivated by how best to handle sorites cases. Consider the following sorites case. We perceive consecutively three subtly distinct shades of red: $\operatorname{red}_{47}, \operatorname{red}_{48}$, and $\mathrm{red}_{49}$. We cannot perceptually tell the difference between $\mathrm{red}_{47}$ and $\operatorname{red}_{48}$. We cannot perceptually tell the difference between $\operatorname{red}_{48}$ and $\operatorname{red}_{49}$. Yet we can perceptually tell the difference between $\operatorname{red}_{47}$ and $\operatorname{red}_{49}$. Arguably, the best way to explain how this is possible is in virtue of there being a difference in our phenomenal evidence between $\operatorname{red}_{47}$ and $\operatorname{red}_{48}$ (as well as between $\operatorname{red}_{48}$ and $\operatorname{red}_{49}$ ) despite the fact that we cannot directly distinguish these shades. An explanation for

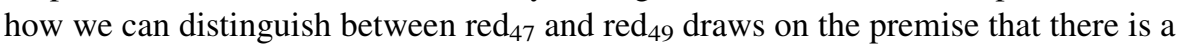
subjectively indiscernible difference between our phenomenal evidence when we perceive $\mathrm{red}_{47}$ and $\mathrm{red}_{48}$, as well as a subjectively indiscernible difference between our phenomenal evidence when we perceive $\operatorname{red}_{48}$ and $\operatorname{red}_{49}$. The idea is that there can be aspects of our phenomenal evidence to which we do not have access. As this case brings out, while it is necessary to reject epistemic transparency if we accept that perceptual states are factive there are reasons to reject the principle even for non-factive mental states. ${ }^{15}$ Given that there are reasons to reject epistemic transparency for non-factive mental states, we need not be troubled that we must reject it if we recognize that experience provides us with factive evidence.

A third rationale in support of rejecting the epistemic transparency principle is that knowledge of one's mental state relies on introspection, and introspection is well known to be an unreliable guide to one's mental states. We mistake itches for

\footnotetext{
${ }^{14}$ For a recent discussion of related issues, see Greco (2014).

15 Some internalists have understood the accessibility of evidence as an essential part of the very nature of evidence. Indeed, it has been argued that denying the accessibility of evidence amounts to changing the subject (Cohen 1984: 284). It will lead too far astray to address this issue here.
} 
pains, we can fail to notice that we are in pain, and we mistake sensations of hunger for feelings of anger. Given that we can be prey to such dramatic errors, it would be astonishing if we were good at noticing the finer differences between perceptual states. $^{16}$

If these considerations are right, then we can say that while perceiving a cup gives us factive evidence that the particular cup is present, we do not in virtue of this know that we have factive evidence of this particular cup. In short, we have factive evidence that it is that cup, without knowing that we have this evidence.

\section{Cases}

Having discussed some implications of the capacity view for justification and epistemic transparency, I will now explore its application to some familiar cases. By thinking through the cases, I will further develop the view, while also displaying its consequences.

\subsection{Identical twins}

Consider a case in which you see $\alpha$ and you know that there is at least one object $\beta$ that is qualitatively indistinguishable from $\alpha$. $\alpha$ and $\beta$ are numerically distinct but qualitatively identical particulars. They are identical twins. For our purposes, $\alpha$ and $\beta$ could be qualitatively identical rubber ducks, coffee cups, or people. ${ }^{17}$

If you see $\alpha$, does your experience justify you in believing it is $\alpha$ ? Or do you need evidence that you are not seeing $\beta$ ? The capacity view posits that your experience gives you at least some prima facie justification for believing it is $\alpha$-even in the absence of evidence that you are not seeing $\beta$. After all, you see $\alpha$ and as a consequence you have phenomenal and factive evidence that $\alpha$ is where you see it to be.

While one does not need evidence that one is not seeing $\beta$ to have evidence that one is seeing $\alpha$, the concern that one might be seeing $\beta$ can arise when there is positive reason to suspect that what one is seeing is $\beta$. You might, for example, be told (falsely) that $\beta$ was at the very location at which $\alpha$ is now, suggesting that you are in fact not seeing $\alpha$, but rather $\beta$. So you might gain misleading evidence that you are seeing $\beta$. In such a case you have a potential defeater of your prima facie justification for the claim that you are seeing $\alpha$.

Even if you have such misleading evidence, you still have factive evidence that it is $\alpha$. So the evidence you have in support of the belief that the object is $\alpha$ is unchanged. Two things change if you have misleading evidence that you could be seeing $\beta$. First, you have additional evidence that may affect what overall credence you should invest in the claim that $\alpha$ is present. Second, you have additional

\footnotetext{
${ }^{16}$ For a more general discussion of the limits and unreliability of introspection, see Pereboom (1994), Goldberg (2000), Bar-On (2004), Schwitzgebel (2008), Fumerton (2009) and Gertler (2011).

17 To keep issues of personal identity out of the picture, I will focus on inanimate objects. Putting aside issues specific to personal identity, everything said about inanimate objects carries over to persons.
} 
evidence in support of the belief that the object is $\beta$ and so not $\alpha$. While both changes affect the degree to which you are ultima facie justified in believing that the object is $\alpha$, there is no reason to think that they affect the factive evidence you have of $\alpha$ in virtue of seeing $\alpha$. So there is no challenge to the claim of prima facie justification. $^{18}$

The token content of the perceiver's mental state will differ, depending on what particular she is perceptually related to. On the capacity view, the token content counterfactually varies with the world. So what factive evidence one has is counterfactually sensitive to the world to which one is perceptually related. In $\mathrm{W}_{1}$ with object $\alpha$, we have content $C_{1}$. If the world changes to $W_{2}$ with object $\beta$, we have distinct content $\mathrm{C}_{2}$, however close $\mathrm{W}_{1}$ and $\mathrm{W}_{2}$ are. What evidence one has determines what one has justification to believe. So I am arguing that even though we cannot tell whether we are seeing $\alpha$ and not $\beta$, we have (unbeknownst to us) evidence for the presence of $\alpha$ when seeing $\alpha$ and so prima facie justification for the proposition that $\alpha$ is present.

\subsection{Speckled Hen}

In the case of seeing identical twins, one is perceptually related to numerically distinct yet qualitatively identical particulars. One's phenomenal evidence is the same, yet one's factive evidence is distinct. What about a case in which one notices a qualitative difference, but it is not obvious what perceptual capacities one is employing to account for the difference in the sensory character of one's experience? One such case is that in which one first sees a hen with 48 speckles and then sees a hen with 47 speckles (Chisholm 1942).

If one looks at a hen with 48 clearly visible speckles, one is causally related to 48 speckles. Most human perceivers, however, do not have the capacity to subitize 48 speckles, that is, they do not have the capacity to rapidly and accurately judge how many objects there are in a group of 48 objects. The subitizing range for most human perceivers lies at around 4 objects. Of course, they could count the speckles, but that is an entirely different cognitive task from assessing the number of speckles at a glance. The difference between seeing a hen with 3 clearly visible speckles and seeing a hen with 48 speckles will help explain the issue. In the former case, we can be aware that the hen has exactly 3 speckles on the basis of seeing the hen, and so we can have phenomenal evidence that the hen has 3 speckles. We can visually discriminate an object that has 3 speckles from one that has 2 speckles. Similarly, we can visually discriminate an object that has 3 speckles from one that has 4 speckles. So we can visually discriminate that there are 3 objects from relevant alternatives. In the case of seeing a hen with 48 speckles, we are not aware that the hen has exactly 48 speckles. After all, we cannot visually discriminate an object that has 48 speckles from relevant alternatives, for instance, an object that has 47 speckles or one that has 49 speckles. So we do not have phenomenal evidence that the hen has exactly 48 speckles.

18 Thanks to Dan Greco for helpful discussions on these issues. 
We are, however, aware that the hen has lots of speckles. Perhaps we are aware that it has more than 30 speckles and less than 80 speckles. To appreciate the subtlety of the problem consider the fact that the sensory character of our experience when we see a hen with 48 speckles can be different from the sensory character of our experience when we see a hen with 47 speckles. So even if we cannot subitize the number of speckles and even if we cannot say specifically what changed between two scenarios, we can tell that there is some difference in a scenario on the basis of how the scenario looks to us. We can tell that there is some difference if we first see a hen with 48 speckles, and then see the very same hen with one less speckle. To be sure, I am not saying that we always notice such a difference, but just that we can notice such a difference. Moreover, I am not saying that there is always a difference in our sensory character. I am saying only that there can be a difference in the sensory character of seeing a hen with 48 speckles and seeing a hen with 47 speckles. The fact that there can be such a difference is enough for our purpose.

I will argue that one does not have factive or phenomenal evidence that the hen has 48 speckles, but that one nonetheless can have both factive and phenomenal evidence that the 48-speckled hen is differently speckled than the 47-speckled hen. What accounts for the possible difference in sensory character between seeing a 47-speckled hen and a 48-speckled hen? If the sensory character of experience is grounded in the content of experience, as representationalists have it, then the difference in sensory character will be due to a difference in perceptual content. I will here presuppose such a representationalist view of sensory character, that is, a view on which the sensory character of experience is grounded in the representational content of experience. ${ }^{19}$

Given this presupposition, the question about sensory character becomes a question about what we represent when we are perceptually related to a hen with 48 clearly visible speckles. One option might be to say that we represent 48 speckles simply as a consequence of being causally related to the hen and the hen having 48 clearly visible speckles. ${ }^{20}$ But this cannot be right. After all, we are causally related to all sorts of things in perception, which we do not represent since we do not have any visual access to them or since we do not notice them: ultraviolet light rays, the microphysical structure of objects, the speck of dust on the floor next to the hen that is visible but which we do not notice. It would be odd to say that we represent all those things.

The condition for representing $\alpha$ must be more constrained than being causally related to $\alpha$. Two possible constraints are that we represent only what is detectable to the perceiver and that we represent only what the perceiver notices. In contrast to ultraviolet light rays and the microphysical structure of objects, the 48 speckles are detectable to the perceiver. In contrast to the speck of dust on the floor, the perceiver notices the speckles on the hen-as the case has it. So the idea is that we represent

\footnotetext{
${ }^{19}$ For a defense of such a view, see my (2011b) and (2014b). See also Dretske (1995), Tye (1995), Byrne (2001), Chalmers (2006) and Pautz (2010).

${ }^{20}$ For a discussion of such an approach, see McGrath (2013).
} 
$\alpha$, only if $\alpha$ satisfies the following three conditions: the perceiver is causally related to $\alpha, \alpha$ is detectable to the perceiver, and the perceiver notices $\alpha$.

Perceiving the hen with the 48 speckles satisfies all these conditions, yet the fact that we cannot subitize 48 speckles is reason to believe that, nonetheless, we do not represent 48 speckles. As noted above, there can, however, be a difference in sensory character between seeing a hen with 48 speckles and one with 47 speckles. If there is such a difference in sensory character, there will be-assuming a representationalist view of sensory character-at least some difference with regard to the content of the experience.

What further constraint could we invoke to account for this difference in perceptual content? To address this question, let's take a closer look at what it is we discriminate between when we see first a hen with 48 speckles and then one with 47 speckles. One kind of capacity is to discriminate between having 48 speckles and having 47 speckles. Another kind of capacity is to discriminate between a scenario that includes a hen with 48 speckles and a scenario that includes a hen with 47 speckles. While we cannot subitize 48 speckles and 47 speckles, we can visually tell the difference between the two scenarios, even if the only difference is one speck on a speckled hen. We employ at least some distinct perceptual capacities and this explains why the sensory characters of the two experiences differ. There are several options for specifying just what the difference is in the perceptual capacities employed. If what we notice is that there is a speck on the first hen that is not present on the second hen, then the difference in the perceptual capacities employed will be that we employ the perceptual capacity to single out that speck when seeing the first hen, but do not employ that perceptual capacity when seeing the second hen.

An alternative option is that we employ the perceptual capacity or demonstrative concept SO-SPECKLED when seeing the two speckled hens. We can understand such a demonstrative concept as a particular kind of perceptual capacity. Like perceptual capacities, demonstrative concepts are individuated by what they single out. Since the hens are speckled differently, the relevant demonstrative concept will be different when we see the 48-speckled hen compared to when we see the 47-speckled hen. The difference in the demonstrative concepts employed accounts for the difference in sensory character and thus accounts for the difference in factive evidence.

These are just two viable options. There are sure to be many more. Both strategies explain how it can be that one does not have factive or phenomenal evidence that the hen has 48 speckles, but nonetheless can have both factive and phenomenal evidence that the 48-speckled hen is differently speckled than the 47-speckled hen. For our purposes that is all we need.

\subsection{Evil Demon Scenario}

Consider Descartes's case in which your perceptual experiences are false experiences presented to you by an evil demon. There are two central questions. Is the capacity view compatible with you having evidence if you inadvertently find 
yourself in such a scenario? And what evidence do you have when, unbeknownst to you, the evil demon presents you with false experiences?

The capacity view is compatible with accepting that the victim of the evil demon has evidence. After all, the idea that phenomenal states are systematically linked to what they are of in the good case requires only that there is the possibility of getting things right in the good case. That is compatible with there not being any actual good cases. Insofar as the mere possibility of good cases is sufficient, the capacity view is compatible with the victim having evidence.

Now one might argue against the view developed in this paper that actual good cases are required for the possession of perceptual capacities. On such a view, the capacity view is not compatible with the victim of the evil demon having evidence. However, given that the possession of perceptual capacities is not understood phylogenetically or ontogenetically, there is no reason to require actual good cases. After all, the victim has properly functioning capacities despite being presented with false experiences. He is simply unlucky.

In light of this response to the first question, we can now address the question of what evidence a victim has who suffers perceptual experiences at the hands of an evil demon. The victim of the demon has phenomenal evidence but no factive evidence beyond the propositions one might still know in an evil demon scenario, such as, "I think, therefore I am". He has no factive evidence beyond such propositions, since he does not perceive external mind-independent particulars and so will fail to single out any such particulars when employing perceptual capacities.

\subsection{Brain in a vat}

Can an envatted brain hallucinate? An envatted brain cannot perceive; it does not have the sensory organs to do so. But it could possess perceptual capacities, despite never being able to use them accurately. After all, perceptual capacities are not tied to the proper functioning of sense organs or even their existence. As long as the envatted brain has perceptual capacities that ground the ability to perceptually single out particulars-should the envatted brain be connected to the necessary sensory organs - then there is no reason to think that the envatted brain could not have hallucinations. Insofar as the brain in a vat can hallucinate, it has phenomenal evidence.

\subsection{New Evil Demon Scenario}

An analysis analogous to the one given of the Evil Demon Scenario can be given of the New Evil Demon Scenario (Lehrer and Cohen 1983; Cohen 1984). Consider Matt who finds himself entrapped in a matrix. The matrix looks just like the real world to Matt, but it is in fact a computer-generated world in which he is unwittingly entrapped. Let's say that Matt is programmed to have a sensory state as of a white cup. Let's say moreover that his counterpart in the real world sees a white cup. So Matt has the same sensory experience as his counterpart in the real world, who sees a white cup. But his counterpart perceives what he seems to see, whereas Matt is trapped in a Matrix. So Matt's counterpart has evidence that is truth- 
conducive, while Matt's evidence is not truth-conducive. Indeed, Matt's experiences are systematically misleading. So while Matrix Matt has the same sensory state as his counterpart in the real world, he does not have the same evidence. Matt has only phenomenal evidence, whereas his counterpart in the real world has both phenomenal and factive evidence.

Now there are ways of understanding the New Evil Demon Scenario on which it is stipulated that the person trapped in the Matrix has the very same evidence as his counterpart in the real world, who is in the good case. I am here following the common interpretation of the New Evil Demon Scenario on which the person in the Matrix and his counterpart have the same sensory experience. Having the same sensory experience is compatible with having different evidence. After all, having the same sensory experience is compatible with being in mental states with different content if the relationship between the sensory character and the content of an experience is not identity but rather supervenience. If the sensory character of experience supervenes on the content of experience, there can be differences in content that are not reflected in sensory character. ${ }^{21}$ Moreover, if the content of one's mental state determines one's evidence, then a view on which the sensory character of experience supervenes on the content of experience will allow that two beings whose experiences have the same sensory character do not have the exact same evidence.

So the capacity view respects the key internalist intuition that an internal duplicate will have the same evidence. However, according to the capacity view, Matt in the Matrix and his counterpart in the real could never be internal duplicates. After all, Matt is in the bad case and his counterpart is in the good case. So Matt fails to single out any particulars, while his counterpart singles out the particulars he purports to single out. Therefore, Matt and his counterpart could never have exactly the same mental state and so could never have exactly the same overall evidence. While they have the same phenomenal evidence, Matt's counterpart has additional factive evidence. This externalist response to the New Evil Demon Problem differs from traditional externalist responses (see Goldman 1993; Sosa 1991; Bergmann 2006) insofar as it rejects the claim that Matt and his counterpart could have the very same evidence, while accepting that the content of one's mental state determines one's evidence.

\subsection{Swampman}

Can Swampman possess perceptual capacities and so have phenomenal and factive evidence? Swampman is a being that came into existence through a bolt of lightning and so has no causal history (Davidson 1987). According to the view developed here, no past experiences are necessary to possess perceptual capacities. Since possessing perceptual capacities does not depend on a history of proper usage - or any usage for that matter-and since perceptual capacities are not understood in an evolutionary way, there is no reason to think that Swampman could not possess the perceptual capacities in play. After all, the condition for their possession is

$\overline{{ }^{21} \text { For a defense of such a weak representationalist view, see Schellenberg }}(2010,2013 \mathrm{~b})$. 
understood counterfactually: if one possesses the capacity to single out red, then one would be able to single out an instance of red, were on related to such an instance. Since Swampman possess the relevant perceptual capacities, he can through perception gain phenomenal and factive evidence about the swampy world around him.

\subsection{Veridical hallucinations}

Consider Vernon. Vernon suffers a veridical hallucination as of a white cup. He hallucinates a white cup at location $\mathrm{L}_{1}$ and as it so happens, there is a white cup behind a screen just where he hallucinates a white cup to be. Since the actual white cup is behind a screen, he could not be perceptually related to it. So the cup at $\mathrm{L}_{1}$ is not causally relevant in bringing about his hallucination. On the basis of his hallucination, he forms the belief that there is a white cup at $\mathrm{L}_{1}{ }^{22}$

The capacity view provides a way to do justice to internalist and externalist intuitions about this case. On the capacity view, Vernon employs the very same perceptual capacities that he would employ, were he perceiving a white cup. As a consequence, he is in a mental state with content that provides him with phenomenal evidence that there is a white cup at $\mathrm{L}_{1}$. So the capacity view can explain in virtue of what Vernon is not blameworthy for his belief that there is a white cup at $\mathrm{L}_{1}$. He is not blameworthy, since he has phenomenal evidence. The view explains, how it is that Vernon does not have knowledge. He does not have knowledge since he does not have factive evidence. He does not have factive evidence, since he is not perceptually related to the white cup at $\mathrm{L}_{1}$.

\subsection{Barn façade county}

Consider Henry, who sees a barn on the road ahead. As it happens, it is the only barn in a county in which there are many barn façades (see Goldman 1976). What evidence does Henry have? Henry employs his capacity to single out the barn he sees, and since he is perceptually related to that very barn, he has both phenomenal and factive evidence of the barn. But does Henry have knowledge in virtue of having factive evidence? A standard analysis of the case is that Henry has a justified true belief that there is a barn on the road ahead, but that he does not know that there is a barn, since his belief is false in most of the closest non-actual cases. The capacity view is compatible with this standard response: having factive evidence is compatible with failing to know. After all, one might add a sensitivity requirement on knowledge. ${ }^{23}$

\footnotetext{
22 This case differs from BonJour's (1980) Norman case, since there is no assumption that Vernon comes at her hallucination by way of a reliable process. By contrast clairvoyant Norman comes to his beliefs by way of a reliable process that however is not based on any evidence or reasons.

${ }^{23}$ Given that one has factive evidence, one already has (at least some) safety. One has safety since singular content entails its truth. So arguably adding a safety requirement on knowledge would not be an option for the capacity view. One might argue however that there is a safety condition on the content type. If that is right, then the capacity view is compatible with a safety requirement on knowledge. We can remain neutral on this issue here.
} 
While the capacity view is compatible with the standard analysis, it also compatible with positing that Henry has a kind of primitive knowledge when seeing the barn in barn façade county. After all, one might argue that having factive evidence is sufficient for a primitive kind of knowing. Such an analysis would mirror Sosa's account of the case. Sosa argues that Henry has animal knowledge but lacks more sophisticated reflective knowledge.

The capacity view is committed to Henry having factive evidence, but compatible both with denying that he has knowledge as well as with granting that he has a certain primitive knowledge. While the view is compatible with these two analyses, the former is more attractive. It is more attractive, since it brings out that the capacity view provides a way of saying that you are in a better epistemic position when you see the barn without yet saying that you necessarily have knowledge. This shows that the notion of factive evidence is epistemically interesting and valuable beyond amounting to knowledge.

Whether having factive evidence is sufficient for having knowledge is a question we can leave open here. Regardless of what stance we take on the question of whether Henry has knowledge in virtue of having factive evidence, we can say that although Henry has factive evidence, he may also have defeaters. After all, he is in barn façade county. One might argue that the sheer existence of the barn façades constitutes a defeater, regardless of whether Henry knows about them. But even if we grant this, the defeaters are not undercutting defeaters, but rather mere rebutting defeaters. So although Henry may have such defeaters, it will not affect what evidence he has regarding the barn. It will affect only what he ends up being justified to believe, all things considered.

\section{Conclusion}

Perceptions guide our actions and provide us with evidence of the world around us. Hallucinations can mislead us: they may prompt as to act in ways that do not mesh with the world around us and they may lead us to form false beliefs about that world. The capacity view provides an account of evidence that does justice to these two facts. It shows in virtue of what hallucinations mislead us and prompt us to act. Moreover, it shows in virtue of what we are in a better epistemic position when we perceive than when we hallucination. When we hallucinate and when we perceive our sensory states provide us with phenomenal evidence. When we perceive we have additional factive evidence. Phenomenal evidence and factive evidence are both kinds evidence that are world-directed due to being constituted by capacities that are world-directed. While factive evidence cannot by its very nature be false, phenomenal evidence can be false. This discrepancy between phenomenal and factive evidence can be fruitfully exploited in analyzing the upshot of the capacity view for a range of familiar cases. As I aim to have shown, the capacity view respects our intuitions about these cases.

Perceptual experience plays at least three different roles in our lives. It justifies our beliefs about our environment. It brings about conscious mental states. And it converts variant informational input, such as light and sound waves, into 
representations of features that we attribute to the world. The capacity view provides a unified account of the epistemological, phenomenological, and informational role of perceptual experience that is sensitive to the scientific evidence about perceptual experience. Phenomenal evidence and factive evidence are each grounded in the perceptual capacities we employ in experience. By grounding the epistemic force of experience in facts about the metaphysical structure of experience, the capacity view is not only an externalist view, but moreover a naturalistic view of the epistemology of perceptual experience. So it is an externalist and naturalistic alternative to reliabilism.

Acknowledgments I am grateful to James Genone and Dan Greco for comments on a draft of this paper as well as audiences at the Evidence workshop in Philadelphia and The Epistemology of Perception workshop at SMU.

\section{References}

Bar-On, D. (2004). Externalism and self-knowledge: Content, use, and expression. Nous, 38, 430-455. Bergmann, M. (2006). Justification without awareness. Oxford: Oxford University Press.

BonJour, L. (1980). Externalist theories of empirical knowledge. Midwest Studies in Philosophy, 5, 53-73.

Burge, T. (2003). Perceptual entitlement. Philosophy and Phenomenological Research, 67, 503-548.

Byrne, A. (2001). Intentionalism defended. The Philosophical Review, 110, 199-240.

Byrne, A. (2014). Perception and evidence. Philosophical Studies.

Byrne, A., \& Hilbert, D. (2003). Color realism and color science. Behavioral and Brain Sciences, 26, $3-21$.

Chalmers, D. (2006). Perception and the fall from eden. In Gendler, \& Hawthorne (Eds.).

Chisholm, R. (1942). The problem of the speckled hen. Mind, 51, 363-373.

Cohen, S. (1984). Justification and truth. Philosophical Studies, 46, 279-296.

Davidson, D. (1987). Knowing one's own mind. Proceedings and Addresses of the American Philosophical Association, 60, 441-458.

Dretske, F. (1995). Naturalizing the mind. Cambridge, MA: MIT Press.

Feldman, R., \& Conee, E. (1985). Evidentialism. Philosophical Studies, 48, 15-34.

Fumerton, R. (2009). Luminous enough for a cognitive home. Philosophical Studies, 142, 67-76.

Gertler, B. (2011). Self-knowledge. London: Routledge.

Goldberg, S. (2000). Externalism and authoritative knowledge of content: a new incompatibilist strategy. Philosophical Studies, 100, 51-79.

Goldman, A. (1976). Discrimination and perceptual knowledge. The Journal of Philosophy, 73, 771-791.

Goldman, A. (1979). What is justified belief? In G. Pappas (Ed.), Knowledge and justification. Dordrecht: Reidel.

Goldman, A. (1986). Epistemology and cognition. Cambridge, MA: Harvard University Press.

Goldman, A. (1993). Epistemic folkways and scientific epistemology. Philosophical Issues, 3, 271-285.

Graham, P. (2011). Epistemic entitlement. New Jersey: Nous.

Greco, J. (2001). Virtues and rules in epistemology. In Fairweather, \& Zagzebski (Eds.).

Greco, J. (2010). Achieving knowledge: A virtue-theoretic account of epistemic normativity. Cambridge: Cambridge University Press.

Greco, D. (2014). Could KK be OK?. Journal of Philosophy, 111, 169-197.

Huemer, M. (2007). Compassionate phenomenal conservatism. Philosophy and Phenomenological Research, 74, 30-55.

Kaplan, D. (1989). Demonstratives \& afterthoughts. In J. Almog, J. Perry \& H. Wettstein (Eds.), Themes from Kaplan. Oxford: Oxford University Press.

Lehrer, K., \& Cohen, S. (1983). Justification, truth, and coherence. Synthese, 55, 191-207.

Lyons, J. (2009). Perception and basic beliefs: Zombies, modules and the problem of the external world. Oxford: Oxford University Press. 
McDowell, J. (1982). Criteria, defeasibility, and knowledge. Proceedings of the British Academy, 68, 455-479.

McGrath, M. (2013). Dogmatism, underminers and skepticism. Philosophy and Phenomenological Research, 86, 533-562.

McGrath, M., \& Fantl, J. (2002). Evidence, pragmatics, and justification. The Philosophical Review, 111, 67-94.

McGrath, M., \& Fantl, J. (2009). Knowledge in an uncertain world. Oxford: Oxford University Press.

Millar, A. (2008). Perceptual-recognitional abilities and perceptual knowledge. In Adrian Haddock \& Fiona Macpherson (Eds.), Disjunctivism: Perception, action, knowledge. Oxford: Oxford University Press.

Nagel, J. (2013). Knowledge as a mental state. Oxford Studies in Epistemology, 4, 273-308.

Neta, R. (2003). Contextualism and the problem of the external world. Philosophy and Phenomenological Research, 66, 1-31.

Neta, R. (2008). What evidence do you have? British Journal for the Philosophy of Science, 59, 89-119.

Pautz, A. (2010). Why ezplain visual experience in terms of content? In B. Nanay (Ed.), Perceiving the world. Oxford: Oxford University Press.

Pereboom, D. (1994). Bats, brain scientists, and the limitations of introspection. Philosophy and Phenomenological Research, 54, 315-329.

Pollock, J. (1974). Experience and justification. Princeton, NJ: Princeton University Press.

Pryor, J. (2000). The skeptic and the dogmatist. Noûs, 34, 517-549.

Schellenberg, S. (2010). The particularity and phenomenology of perceptual experience. Philosophical Studies, 149, 19-48.

Schellenberg, S. (2011a). Ontological minimalism about phenomenology. Philosophy and Phenomenological Research, 83, 1-40.

Schellenberg, S. (2011b). Perceptual Content defended. Nô̂s, 45, 714-750.

Schellenberg, S. (2013a). Experience and evidence. Mind, 122, 699-747.

Schellenberg, S. (2013b). Externalism and the gappy content of hallucination. In F. E. Macpherson \& D. Platchias (Eds.), Hallucination (pp. 291-311). Cambridge: MIT Press.

Schellenberg, S. (2014a). The epistemic force of perceptual experience. With a response by Alex Byrne, Philosophical Studies.

Schellenberg, S. (2014b). The relational and representational character of perceptual experience. In B. Brogaard (Ed.), Does perception have content?. New York: Oxford University Press.

Schwitzgebel, E. (2008). The unreliability of introspection. Philosophical Review, 117, 245-273.

Silins, N. (2005). Deception and evidence. Philosophical Perspective, 19, 375-404.

Smithies, D. (2012). Mentalism and epistemic transparency. Australasian Journal of Philosophy, 90, $723-741$.

Sosa, E. (1991). Knowledge in perspective. Cambridge: Cambridge University Press.

Sosa, E. (2006). Internal foundations or external virtues? Philosophical Studies, 131, 733-769.

Sosa, E. (2007). A virtue epistemology: Apt belief and reflective knowledge. New York: Oxford University Press.

Tye, M. (1995). Ten problems of consciousness: A representational theory of the phenomenal mind. Cambridge, Mass.: MIT Press.

Williamson, T. (2000). Knowledge and its limits. Oxford: Oxford University Press. 